\title{
Structural Statics Analysis and Optimization Design of Regulating Device for Air Conveyer Outlet in Coal Mine
}

\author{
Xiaoyan GONG Ying LI Yongqiang ZHANG \\ School of Mechanical Engineering, Xi'an University of Science and Technology, Xi'an, Shanxi 710054, China
}

\begin{abstract}
In view of the enlargement of fully mechanized face excavation and long distance driving, gas emission and dust production increase greatly. However, the current ventilation device direction angle, caliber and front-back distance cannot change dynamically at any time, resulting in the serious accumulation in the dead zone. In this paper, a new device were proposed that can solve above problems. Finite element ANSYS software were used to simulate and optimize the structural safety of the control device' key components. The optimization results showed that the equivalent stress decreases by $49 \%$; after the optimization of deformation and mass are $0.829 \mathrm{~mm}$ and $0.548 \mathrm{~kg}$, which were $21 \%$ and $10 \%$ lower than before.The quality、safety、 reliability and cost of the control device reach the expected standards perfectly, which can meet the requirements of safe ventilation and down-dusting of fully mechanized face.
\end{abstract}

\section{Introduction}

With the expansion of fully mechanized excavation face and long distance tunneling, the gas emission and dust production increased significantly. At present, the installation of the ventilation device was located on the sidewall of the roadway. The outlet angle, diameter and front-back distance could not be changed at any time. Resulted in the serious accumulation of gas dust in the dead zone, safety and environmental pollution increased risk.[1-3]. For this reason designed digging duct outlet control device, through the scientific adjustment angle,
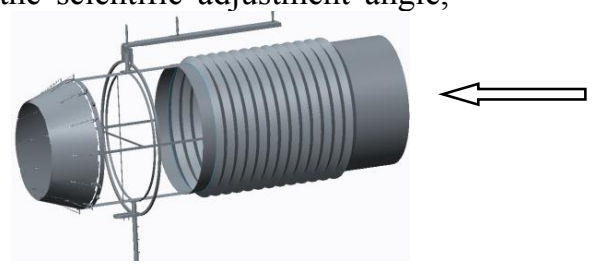

Figure1 outlet control device three-dimensional model

\section{Device Structure Safety Analysis}

\subsection{Structural Design}

Control device of the three-dimensional model shown in Fig1. The inner diameter adjustment blade has a thickness of $0.5 \mathrm{~mm}$, a length of $400 \mathrm{~mm}$ and an arc length of $400 \mathrm{~mm}$; the outer diameter adjustment blade has a

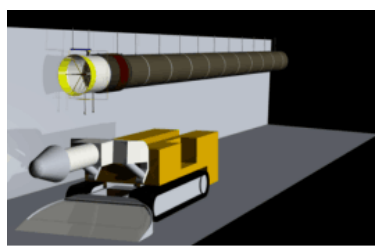

diameter and front and rear distance to change the direction speed of the wind flow, thus diluting the gas and dust concentration. In this paper, ANSYS software were used to analyze the blades and frame of the control device. The simulation was carried out to key parts during the actual application of the force situation. Small deformation of the leaves for optimal analysis. It provides a certain basis for the optimization design of regulating device and has important significance for improving ventilation environment of fully mechanized heading face.

Figure 2 manual duct outlet airway model

thickness of $0.5 \mathrm{~mm}$, a length of $400 \mathrm{~mm}$ and an arc length of $400 \mathrm{~mm}$; the main section of the duct frame upper beam thickness $10 \mathrm{~mm}$, width $15 \mathrm{~mm}$, length $530 \mathrm{~mm}$; dial fixed frame width $20 \mathrm{~mm}$, inner diameter $1171 \mathrm{~mm}$, thickness $40 \mathrm{~mm}$;

\subsection{Leaf Structure Safety Analysis}

(1) Finite Element Model

\footnotetext{
*Corresponding author:541657551@qq.com
} 
In the Ansys Workbench to establish a contact relationship, in the outer part of the blade and the inner blade contact with the displacement contact, Fig 3shows a Finite element mesh model. According to the structural design size, structural characteristics and force situation. Lastly, the mesh used chosen tetrahedral configuration and fine enough to contour the curved surfaced of the blade model properly. There were 316531 total element

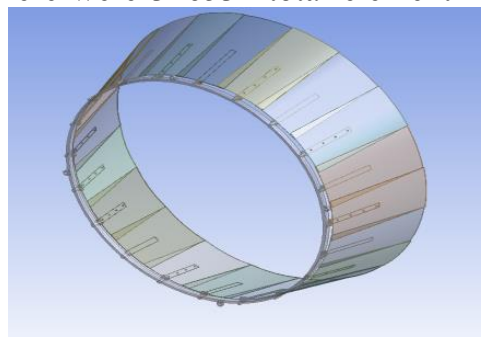

(a) geometry model in place. The material of the blade is Stainless steel, and density: $7.90 \mathrm{~g} / \mathrm{cm}^{3}$; elastic Modulus: $195 G_{p a}$; poisson's ratio: 0.247 ; tensile strength: $\sigma_{b}(\mathrm{MPa}) \geqslant 520$; yield Strength: $\sigma_{0.2}(\mathrm{MPa}) \geqslant 205$, linear elastic material model was used in numerical simulation.

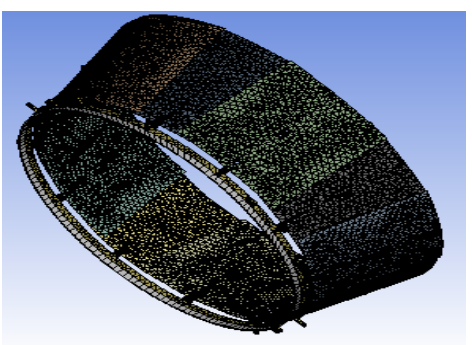

(b)Finite Element Mesh Generation

Figure 3 Blade geometry and meshing

(2) Constraints and Loads

The total weight of the air duct outlet device blade is $22.7 \mathrm{~kg}$ (based on creo simulation software, quality calculation) about $227 \mathrm{~N}$. According to data of Ningtiaota coal mine shows the wind speed of air duct are $10 \mathrm{~m} / \mathrm{s}$ [4-5]. The flaring diameter is $1.2 \mathrm{~m}$, and the diameter at the maximum limit is $1 \mathrm{~m}$. The cross-sectional area is $\mathrm{F}=0.785 \mathrm{~m}^{2}$ Air volume $\mathrm{Q}=$ $7.85 \mathrm{~m}^{3} / \mathrm{s}$. When caliber of the control device is reduced to $0.7 \mathrm{~m}$, the cross-sectional area of the duct is $\mathrm{F}=$

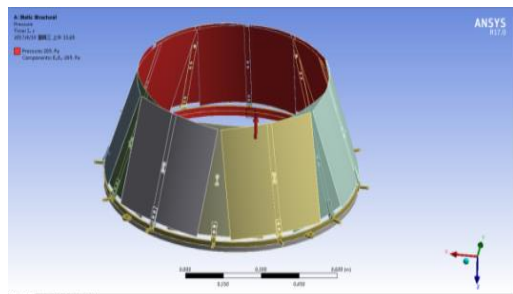

(a)Blade necking state

Figure 4 blade necking, flaring state loading load

(3) Safety Analysis of Blade 's State Structure

Base on CAE analysis software Ansys Workbench calculate solution, we can obtain the stress and strain diagram of control device, as shown in Fig.5.The results showed that maximum deformation of the leaf strain region occurs at the point where the blade has no fixed restraint. The maximum equivalent strain is $0.1345 \mathrm{~mm} / \mathrm{mm}$. The maximum stress of the blade is at the fixed constraint of the outer blade link spring, the maximum stress of the blade is 21.09 pa.The stress of fixed restraint at the bottom of the blade is smaller, about
$0.38465 \mathrm{~m}^{2}$; the head wind speed $\mathrm{V}=\mathrm{Q} / \mathrm{F}=20.4 \mathrm{~m} / \mathrm{s}$. In this limit state, the wind pressure generated by the wind speed is $\mathrm{P}=\mathrm{P} \mathrm{V}^{3} / 2=269 \mathrm{~Pa}$. The blades are fixed on the frame of the control device connect by pins. The inner and outer blades are in displacement contact, the outer blade and the traction rope are connected at a fixed constraint. The maximum wind pressure value under the limit state of $269 \mathrm{~Pa}$. The blade is loaded with a force parallel to the ring with a size of $67.25 \mathrm{~Pa}$ according to the actual situation under flaring, as shown in Fig 4.

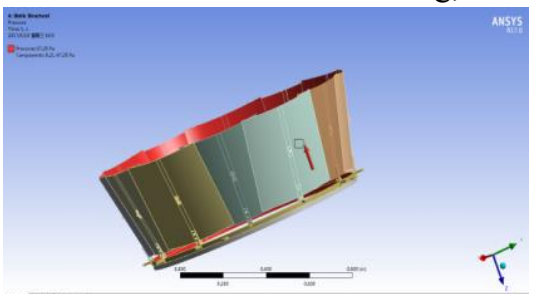

(b)Flared flaps

12.33 pa.The stress at the fixed constraint of the blade's bottom link is about $0.76 \mathrm{~Pa}$. According to the calculation results of blade stress, with the maximum stress of blade as the actual force check(at the most dangerous locations of structural stress value), the safety factor of blade ultimate stress structure strength reaches 9.7 times. According to the performance index of strength and stiffness of the hair dryer, the existing design size is too large, the stress concentration is obviously existed in the blade, and the structure needs to be further optimized.

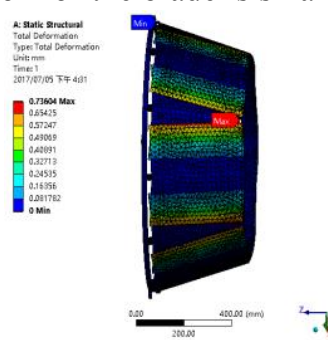

a contraction of the total

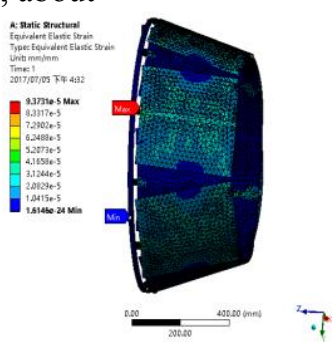

b blade shrinkage

Figure 5 blade necking

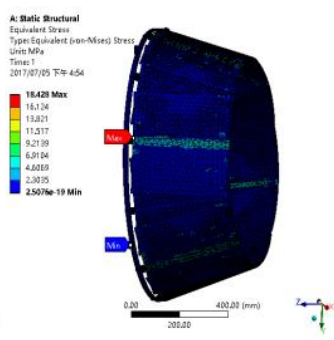

c blade shrinkage 


\subsection{Framework Security Analysis}

(1) Finite Element Model

According to the design dimensions, structural characteristics and stress conditions, the outer frame adopts a shell element for the discrete grid, the total number of divided elements is 87719 . The material of frame and the control rod is Q235 steel, the density is $7.85 \mathrm{~g} / \mathrm{cm}^{3}$, Elastic modulus $200 G_{p a}$, Poisson's ratio 0.3, tensile strength $\sigma_{b}(\mathrm{MPa}) \geq 460$, yield strength $\sigma_{0.2}(\mathrm{MPa}) \geq 235$, linear elastic material model was used in numerical simulation.

(2) Constraints and Loads

The angle steering mechanism to withstand total weight, load $227 \mathrm{~N}$. Frame base to withstand the lifting of the recoil when the air cylinder, when the lifting angle of 6 degrees, the maximum recoil, frame subjected to force $\mathrm{F} 1=\operatorname{mgsin} 6^{\circ}=22.7 \mathrm{~N}$. Because of the outer frame horizontal rotating device is fixed on the slide, a fixed constraint is added to the connection of the horizontal frame of the outer frame; According to the actual situation, the weight of the intelligent is loaded, an overall gravitational acceleration is applied to the whole outer frame. With working conditions, the push rod in the frame contact position is to add a horizontal force, the size of $22.7 \mathrm{~N}$; the overall acceleration of gravity; as shown in Figure 6;

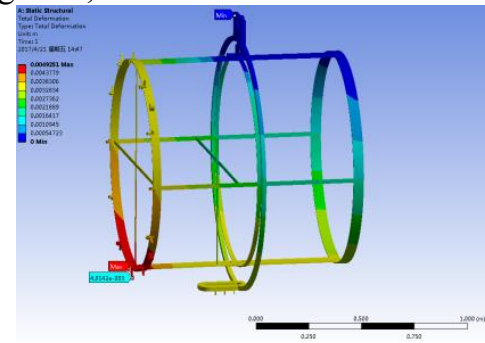

a frame total deformation

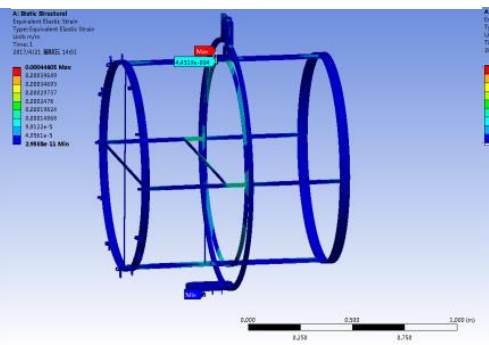

b frame equivalent strain diagram
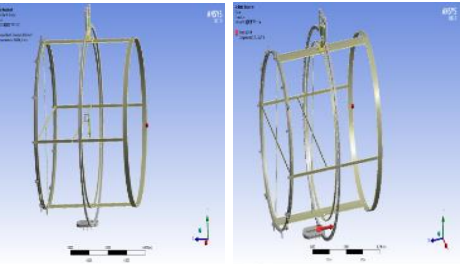

a

c
Figure 6 trame boundary constraints

(3) Frame Structure Safety Analysis

Ansys Workbench calculation solution can get the control device frame stress and strain diagram, shown in Fig 7. The results showed that the main deformation area of the outer frame is at the bottom of the connecting ring between the inner frame and the blade, and the maximum value is about $4.93 \mathrm{~mm}$. The upper middle beam of the outer frame has the largest equivalent strain in the left suspension. The maximum value is about $0.000446 \mathrm{~mm} /$ $\mathrm{mm}$. According to the calculation results of the outer frame stress, the maximum stress value at the connection between the frame and the angle steering mechanism is $17.3 \mathrm{~Pa}$ and the maximum stress value at the fixed constraint of the upper beam is $33.8 \mathrm{~Pa}$. The maximum stress of the frame (the stress value at the most dangerous position of the structure ) for the actual strength of the check, the outer frame of the two locations of the ultimate stress strength of the safety factor of 6.9 times.

Figure 7 framework cloud

\section{3 structure optimization design}

\subsection{Optimization Program Analysis}

The blade is the key part of the entire device. There is a stress concentration phenomenon in the blade from the finite element analysis. The material cost of the blade structure accounts for about $50 \%-65 \%$ of the whole machine, so as to reduce the weight of the blade as much as possible under the premise of meeting the stiffness and strength. In this paper, the size parameters of the blade, the maximum equivalent stress, the total deformation and the mass of the blade are set as the target of the optimization parameters. When the strength requirement is met and the deformation amount is the minimum, the geometrical dimension is the smallest, that is, the thickness is the thinnest.

\subsection{Optimization Analysis}

(1) Parameter Sensitivity Analysis

The results of global sensitivity analysis of this model are shown in Fig.9. The results show that thickness of blade has a great influence on the model stress. The deformation of the blade decreases as the thickness increases. The blade quality and deformation are affected by the thickness, with the increase thickness, the blade mass obviously increases and the blade deformation decreases. Sensitivity analysis results show that in the optimization process the input parameters selected have a significant impact on the output parameters of the model, and optimization was feasible. 


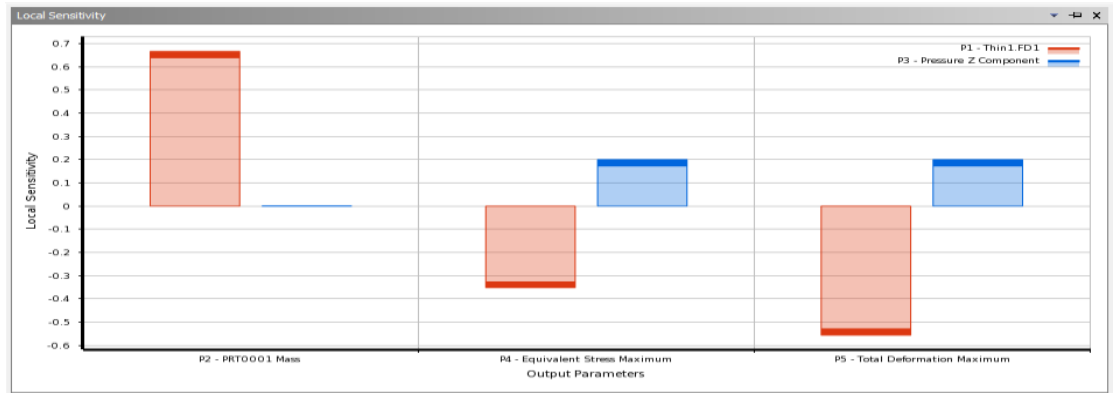

(2) Response Surface Analysis

In this paper, used the response surface analysis method, ANSYS Workbench was to find the equilibrium relationship between input and output parameters. The fitting of wired points by adding response points
[7-8].For the blade model, the thickness is taken as the parameter, the output parameters of the blade mass, total deformation and equivalent stress corresponding to the response surface is obtained through the response surface analysis, as shown in Fig 9.

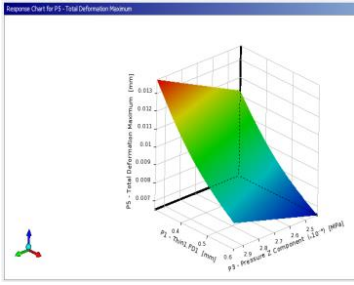

a Thickness deformation load response

Figure 9 Respo

The responses of the input parameters are obtained intuitively from the response surface and the blade thickness has a linear relationship with the deformation. As the blade thickness increases, the amount of deformation gradually decreases. The relationship between the blade thickness and the maximum wind pressure is linear. With the increase of the blade thickness, the maximum wind pressure gradually increases.

(3) Leaf Optimization Analysis

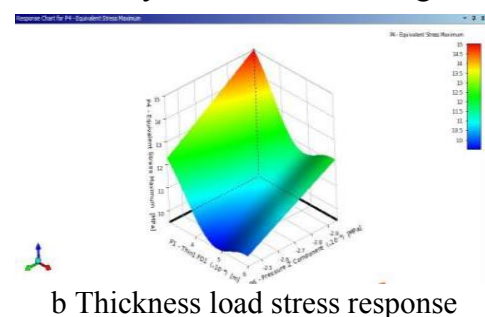

b Thickness load stress response

Through the sensitivity and response surface analysis, we can get the relationship between input and output parameters. Analysis shows that: in ensuring the blade stiffness and strength of the conditions, there is still room for further optimization of blade thickness. The optimization results are shown in Table 1 below. It can be seen from Table 1 that the optimum design points of $\mathrm{A}, \mathrm{B}$ and $\mathrm{C}$ are obtained through optimization calculation under the conditions of satisfying the maximum wind pressure not exceeding $269 \mathrm{~Pa}$, the minimum total deformation and the lightest mass.

Table 1 Optimization Design Calculation Results

\begin{tabular}{|c|c|c|c|c|}
\hline Parameter & A & $\mathrm{B}$ & $\mathrm{C}$ & original plan \\
\hline P1-thin1.FD1 /mm & 0.5 & 0.45 & 0.3 & 0.6 \\
\hline $\mathrm{P} 3$-pressure /MPa & $2.421 *-4$ & $2.69 *-4$ & $2.69 *-4$ & $2.959 *-4$ \\
\hline Max total deformation $/ \mathrm{mm}$ & 7.9421 & 6.892 & 13.417 & 4.075 \\
\hline Max equivalent stress $/ \mathrm{MPa}$ & 6.9 & 11.104 & 16.849 & 52.655 \\
\hline Max equivalent strain $/ \mathrm{mm} / \mathrm{mm}$ & $0.352 *-5$ & $5.6288 *-4$ & $9.4829 *-4$ & $0.2898 *-4$ \\
\hline Mass $/ \mathrm{kg}$ & $0.567856^{*-4}$ & $0.54866^{*}-4$ & $0.36583 *-4$ & $0.73144 *-4$ \\
\hline
\end{tabular}

According to the optimization results in Table 1, the rationality of the scheme is evaluated comprehensively and the best scheme was selected. Above optimization results are in line with the requirements. Compared with the original scheme, the quality of scheme $\mathrm{A}$ is reduced by $10 \%$, the overall deformation is reduced by $21 \%$, the stress concentration is reduced by $49 \%$, the intensity is strengthened, and the initial optimization goal is achieved.

\section{Conclusion}

In this paper, the structural safety numerical simulation and optimization analysis were carried out on the key blade of newly developed control device. The conclusions are as follows:

(1) The outlet vane in the deflated state is $0.1345 \mathrm{~mm}$ / $\mathrm{mm}$, the maximum stress is $21.09 \mathrm{~Pa}$ and the structural strength safety factor is 9.7 times. The maximum equivalent stress in the flared state of the blade is $0.48 \mathrm{~mm} / \mathrm{mm}$, the maximum stress is $6.60 \mathrm{~Pa}$, and the structural strength safety factor is 31 times;

(2) It can be obtained by sensitivity analysis that the overall deformation of the blade decreases as the thickness of the blade increases. The blade quality and deformation are affected by the thickness of the leaves greatest impact. The response surface analysis results are consistent with the sensitivity analysis. According to the analysis, the A group scheme is the best, the maximum 
equivalent stress is reduced by $49 \%$, the total deformation is reduced by $21 \%$ and the quality is reduced by $13.2 \%$, to achieve the purpose of optimization.

\section{Acknowledgements}

Project Support: The paper was supported by the Key Research and Development Plan of Shaanxi Province (2017GY-170) and the Industrialization Program of Shaanxi Provincial Education Department.

\section{References}

1. Jiao Chenlei, Ma Shitai, Yang Xinde, et al.Analysis and optimization of NGW51 planetary gear set based on Ansys and Matlab [J]. Hoisting and transport machinery 2017 (3): 21-23.

2. Gong Xiaoyan, Li Gen, Jiao Wanying et al. Fully mechanized face air duct outlet all-directional control device [P]. Shaanxi: 201610574176.7, 2016-10-13.
3. Zhou L, Pritchard C, Zheng Y. CFD modeling of methane distribution at a continuous miner face with various curtain setback distances [J]. International Journal of Mining Science and Technology, 2015, 25 (4): 635-640.

4. JIA Xiao-quan. Ventilation Distribution and Prevention of Gas Accumulation in Drivage Face $[\mathrm{J}]$.Journal of Shanxi Coal Mining Administrators College, 2012, 25 (2): 38-39.

5. Li Rongrong, Ding Jianwen, Cao Pingxiang.Optimization Design of Large Cross-section Glulam Press Frame with ANSYS Workbench [J]Journal of Northeast Forestry University 2017,14 (11): 62-66.

6. Yao Daozhuang, Yang Jianguo, Lv Zhijun.Optimization design of shelf column section based on ANSYS Workbench [J]Journal of Donghua University (Natural Science Edition), 2011,37 (4): 438-441.

7. Liu Chengjie, Luo Peng, Zhao Lei and other optimization design based on ANSYS Workbench crankpin [J]. Chinese Journal of Applied Mechanics 2017,34 (12): 1141-1144. 